\title{
Antibody Production in Pyridoxin-Deficient Rats
}

\author{
By L. R. C. AGNEW and R. COOK \\ Rowett Research Institute, Bucksburn, Aberdeenshire
}

(Received 30 September 1948)

Stoerk \& Eisen (1946) and Stoerk, Eisen \& John (1947) reported that pyridoxindeficient rats immunized with sheep erythrocytes developed serum-antibody (haemagglutinin) levels far below those of inanition control rats and of rats fed a complete diet ad lib. Axelrod, Carter, McCoy \& Geisinger (1947), using human erythrocytes as an antigenic stimulus, obtained similar results. It seemed of interest to attempt to confirm these findings and to use not only sheep erythrocytes but also a killed culture of a pathogenic organism, Bacterium typhosum. Further, as Stoerk et al. (1947) reported a striking reduction in the number of fixed and circulating lymphocytes in pyridoxindeficient rats, it seemed worth studying the effect of pyridoxin deficiency on lymphoid tissue in the rat, particularly as the work of White \& Dougherty (1946) indicated the importance of the lymphocyte in antibody formation by virtue of the elaboration of $\gamma$-globulin.

\section{METHODS}

\section{Diet and management of rats}

Hooded Lister Institute rats (Rowett Institute strain) of both sexes were used. The animals were weaned and maintained on the synthetic diet shown in Table I. Preliminary studies indicated that a rat fed on the pyridoxin-deficient diet failed to grow as rapidly, owing to anorexia, as a litter-mate receiving the same diet with pyridoxin. Any differences, e.g. in antibody titres or thymus weights, between a pyridoxin-deficient rat and a fully supplemented rat might thus be attributable not only to pyridoxin deficiency but also to inanition. Inanition is not, of course, a specific feature of pyridoxin deficiency and occurs, for example, in deficiency of riboflavin, aneurin and pantothenic acid. Inanition controls were therefore desirable and were used throughout this work, the paired-weighing or paired-feeding technique being used. Each experiment in the present series involved the use of several trios or quartets of litter-mate weanling rats of the same sex and approximately the same weight, the animals in each trio or quartet being arranged thus:

rat no. I, fed the experimental diet ad lib. with all vitamin supplements, rat no. 2, fed the diet ad lib. with all vitamin supplements except pyridoxin, rat no. 3, paired-weighed with rat no. 2 but given pyridoxin;

rat no. 4 , if used, paired-fed with rat no. 2 but given pyridoxin.

The animals were housed in individual cages with wide wire-screened bases and had unlimited access to water. The B-complex vitamins (Table I), except choline, were 
made up in a 'master mix' which was stored at $0-4{ }^{\circ}$. An appropriate amount of this powder was thoroughly mixed with the casein of the diet. 'The animals were weighed daily.

\section{Sheep erythrocytes as antigen}

\section{Antibody experiments}

Thirty weanling rats were used in these studies, the animals being grouped in trios of litter-mates of the same sex and approximately the same weight as indicated above.

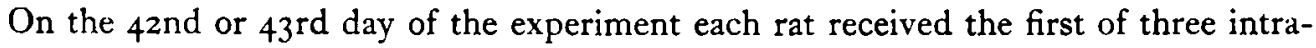
peritoneal injections, which were given on alternate days, of $0.5 \mathrm{ml}$. of a $5 \%$ saline

Table I. Composition of the experimental diet

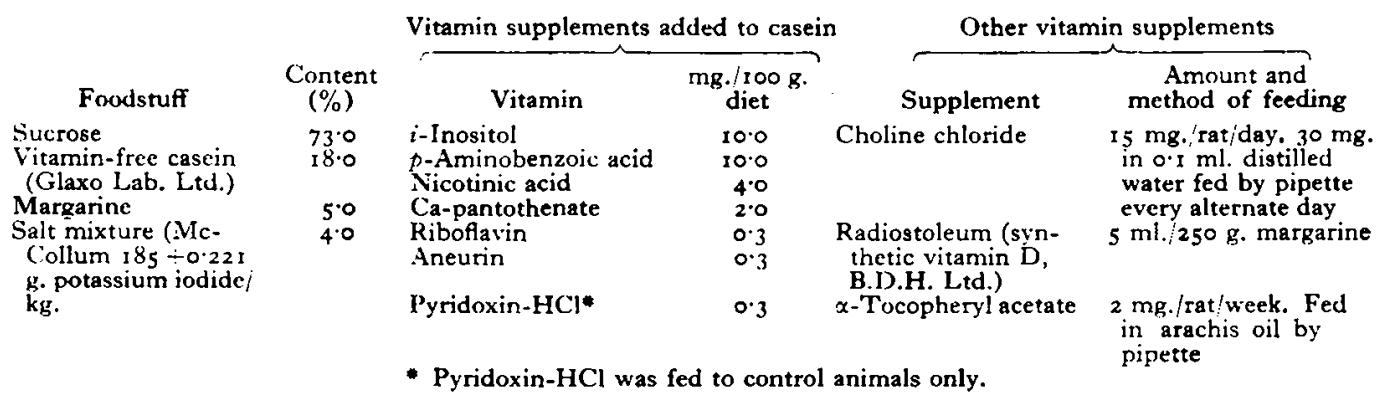

suspension of sheep erythrocytes. Five days after the last injection the rats were bled from the axillary vessels under ether anaesthesia, and the haemagglutinin titre of each serum determined, twofold dilutions from $I$ in 10 to $I$ in 1280 being used.

Bact. typhosum as antigen

Twenty-one weanling rats were arranged in trios as indicated above. In three cases an additional inanition control (paired-fed) was used. On the 43 rd day of the experiment each animal received an intraperitoneal injection of $2.0 \mathrm{ml}$. of a formolized suspension (' $\mathrm{H}$ ' antigen) of Bact. typhosum (strain Kasauli). Ten days later the animals were bled from the axillary vessels under ether anaesthesia and the individual serums agglutinated against a formolized suspension of Bact. typhosum ' $\mathrm{H}$ ' (strain Kasauli). The serums were set up in dilutions $I$ in $25, I$ in $50, I$ in $125, I$ in 250, I in 500, 1 in 1000 , $\mathrm{I}$ in 2500 and I in 5000, incubated for $2 \mathrm{hr}$. at $37^{\circ}$, and allowed to stand overnight at room temperature before the agglutination titres were read.

\section{Effect of pyridoxin deficiency on lymphoid tissue}

Eighteen trios (twelve male, six female) of weanling rats, arranged as above, were used. Representative trios were killed after they had received the diet for periods ranging from 14 to 70 days. The animals were anaesthetized with ether, and blood was taken from the left axillary vein for total and differential white cell counts. The animals were then gassed and the thymus, spleen, submaxillary lymph nodes, and both adrenals carefully dissected out, weighed, and retained for histological examination. Care is particularly required in dissecting out the thymus because of the possibility of mistaking a mediastinal lymph node for part of the thymus (Agnew, 1948). The 
adrenals were fixed in $4 \%(\mathrm{w} / \mathrm{v})$ formalin (ten parts commercial formalin to ninety parts of water) and frozen sections were stained with Scharlach and Sudan black B. The other organs were fixed in Zenker-formol or $2.5 \%(\mathrm{w} / \mathrm{v})$ formol-saline (five parts commercial formalin to ninety-five parts of normal saline) and $4-6 \mu$. paraffin sections stained with haematoxylin and eosin.

\section{RESULTS}

Sheep erythrocytes as antigen

\section{Antibody experiments}

The detailed results are shown in Table 2. Eight of ten pyridoxin-deficient rats had titres less than those of their corresponding ad lib. and inanition controls, one had a titre the same as its inanition control, and only one had a higher titre than its inanition

Table 2. Reciprocals of haemagglutinin titres of rats in different dietary groups

\begin{tabular}{ccccc} 
& \multicolumn{4}{c}{ Dietary group } \\
Sex & Trio no. & $\begin{array}{c}\text { Pyridoxin- } \\
\text { deficient }\end{array}$ & $\begin{array}{c}\text { Paired-weighed } \\
\text { control }\end{array}$ & Ad lib. control \\
M & I & 10 & 80 & 80 \\
M & 2 & 10 & 80 & 80 \\
M & 3 & 0 & 40 & 20 \\
M & 4 & 10 & 20 & 20 \\
M & 5 & 40 & 40 & 20 \\
F & 6 & 0 & 80 & 40 \\
F & 7 & 0 & 80 & 20 \\
F & 8 & 40 & 80 & 80 \\
F & 9 & 40 & 20 & 20 \\
F & 10 & 10 & 20 & 40
\end{tabular}

Table 3. Reciprocals of agglutination titres of rats in different dietary groups immunized with a single injection of Bact. typhosum, ' $H$ ' antigen

\begin{tabular}{|c|c|c|c|c|c|}
\hline \multirow[b]{3}{*}{ Sex } & \multirow[b]{3}{*}{ Trio no. } & \multicolumn{4}{|c|}{ Dietary group } \\
\hline & & \multirow[b]{2}{*}{$\begin{array}{l}\text { Pyridoxin- } \\
\text { deficient }\end{array}$} & \multicolumn{2}{|c|}{ Inanition control } & \multirow[b]{2}{*}{ Ad lib. contro } \\
\hline & & & $\begin{array}{l}\text { Paired- } \\
\text { weighed }\end{array}$ & Paired-fed & \\
\hline $\mathbf{M}$ & I I & 50 & 250 & $\ldots$ & 250 \\
\hline $\mathbf{M}$ & 12 & 50 & 500 & $\ldots$ & 50 \\
\hline $\mathbf{M}$ & 13 & 25 & 2500 & $\ldots$ & 500 \\
\hline $\mathbf{M}$ & 14 & 125 & 500 & 500 & 250 \\
\hline $\mathbf{F}$ & 15 & 250 & 500 & 500 & 500 \\
\hline $\mathbf{F}$ & 16 & $500 *$ & 250 & $25^{\circ}$ & 500 \\
\hline $\mathbf{F}$ & 17 & 250 & 250 & $\ldots$ & 1000 \\
\hline
\end{tabular}

control. The titres of the inanition control animals were in four cases higher than those of the corresponding ad lib. controls, in five cases the same, and in only one case lower.

Bact. typhosum as antigen

The detailed results are shown in Table 3. Five of seven pyridoxin-deficient animals had lower titres than their corresponding inanition controls, one had a titre the same as 
its inanition control, and only one had a higher titre than that of its inanition control. Multiple abscesses were observed in the right lung of the rat in question and Grampositive diptheroid bacilli were seen in pus from these lesions. The high titre obtained was probably an anamnestic response. In three cases the titres of the inanition control animals were higher than those of the corresponding ad lib. controls, in two cases the same, and in two cases lower.

\section{Effect of pyridoxin deficiency on lymphoid tissue}

Striking changes in lymphoid tissue were observed only in the thymus. Fig. I indicates that the thymus glands of the pyridoxin-deficient animals were smaller (g./roo g. body-weight) than those of the corresponding inanition and ad lib. control

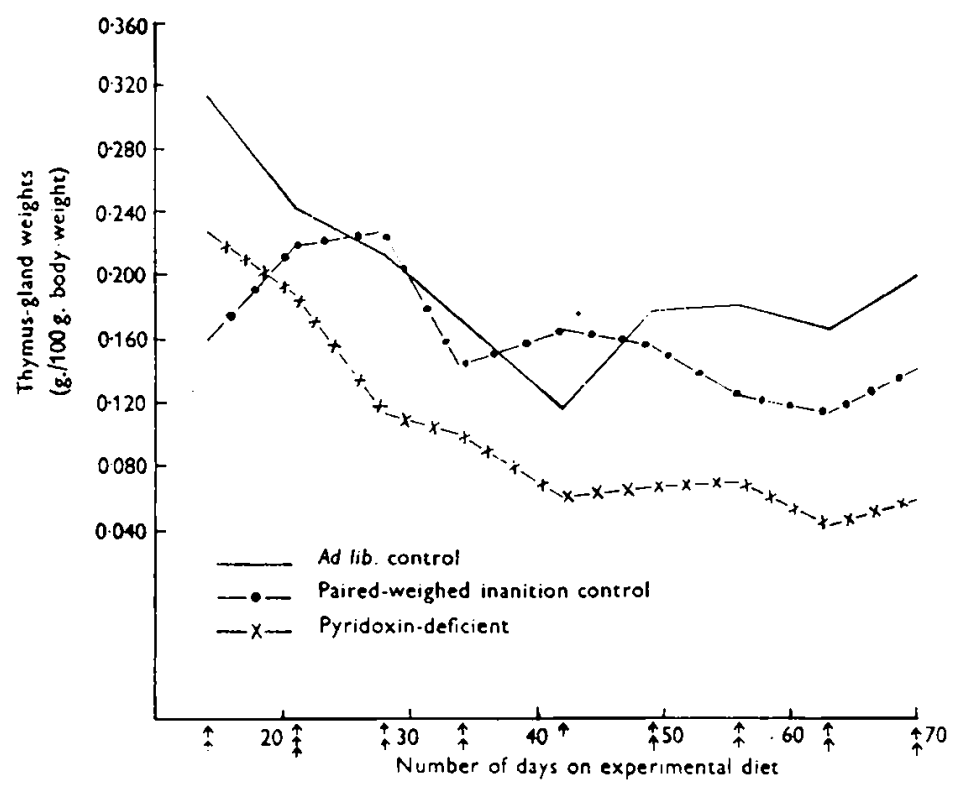

Fig. 1. Thymus gland weights of pyridoxin-deficient rats and of ad lib. and paired-weighed controls, killed after $14^{-70}$ days on experiment. $\uparrow=$ Trio of rats (see text, p. $3^{2}$ ).

animals. Histologically, marked depletion of lymphocytes resulting in a disappearance of cortico-medullary differentiation (Fig. 2) was a feature in most of the thymuses examined. The spleens of the pyridoxin-deficient rats were, if anything, larger (g./100 g. body-weight) than those of the corresponding inanition and ad lib. controls (Fig. 2) and histologically slight depletion of lymphocytes was noted in only a few cases. 'The submaxillary lymph nodes of the pyridoxin-deficient animals did not appear to differ significantly in weight ( $\mathrm{g}$ / / I00 g. body-weight) from those of the corresponding controls (Fig. 3), although histologically these nodes usually showed some depletion of lymphocytes but not as severe as in the thymus. The total white cell counts and lymphocyte counts of the pyridoxin-deficient rats did not differ significantly from those of the corresponding inanition control animals, although the counts in both these groups appeared to be lower than those obtained in the ad lib. control animals (Fig. 4). 
Vol. 2

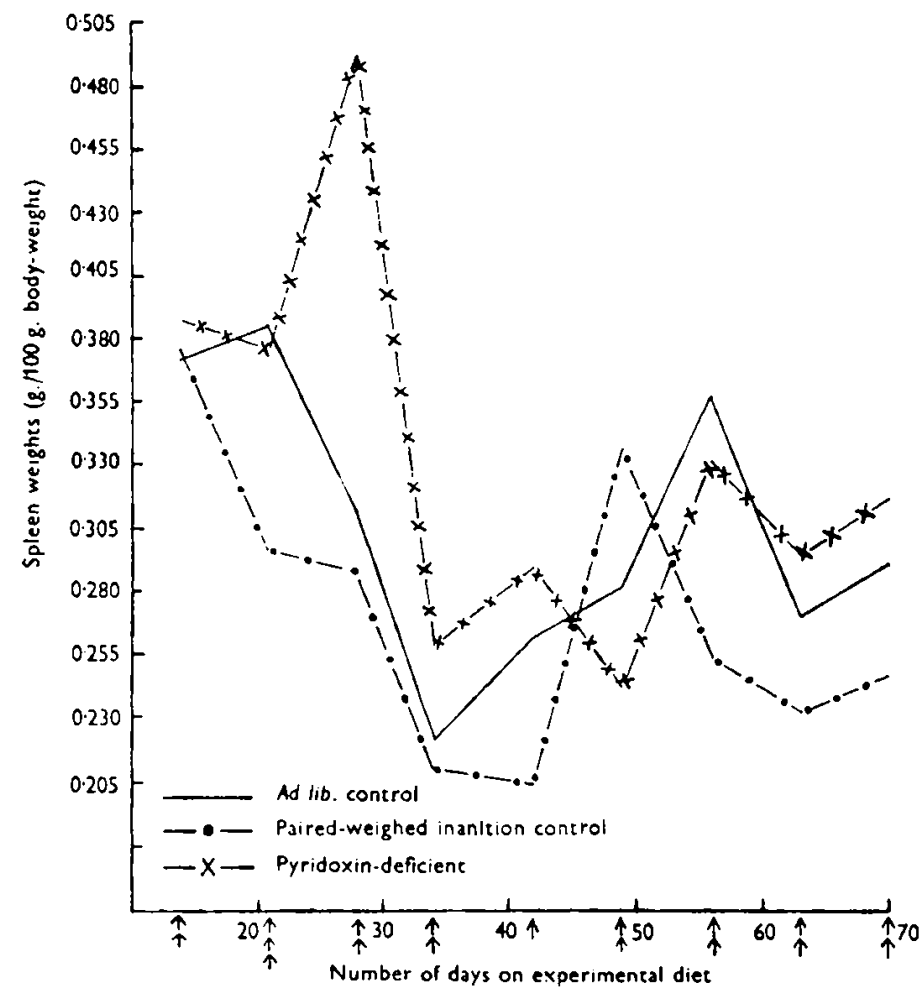

Fig. 2. Spleen weights of pyridoxin-deficient rats and of ad lib. and paired-weighed controls, killed after $14-70$ days on experiment. $\hat{\imath}=$ Trio of rats (see text, p. $32 \mathrm{I}$ ).

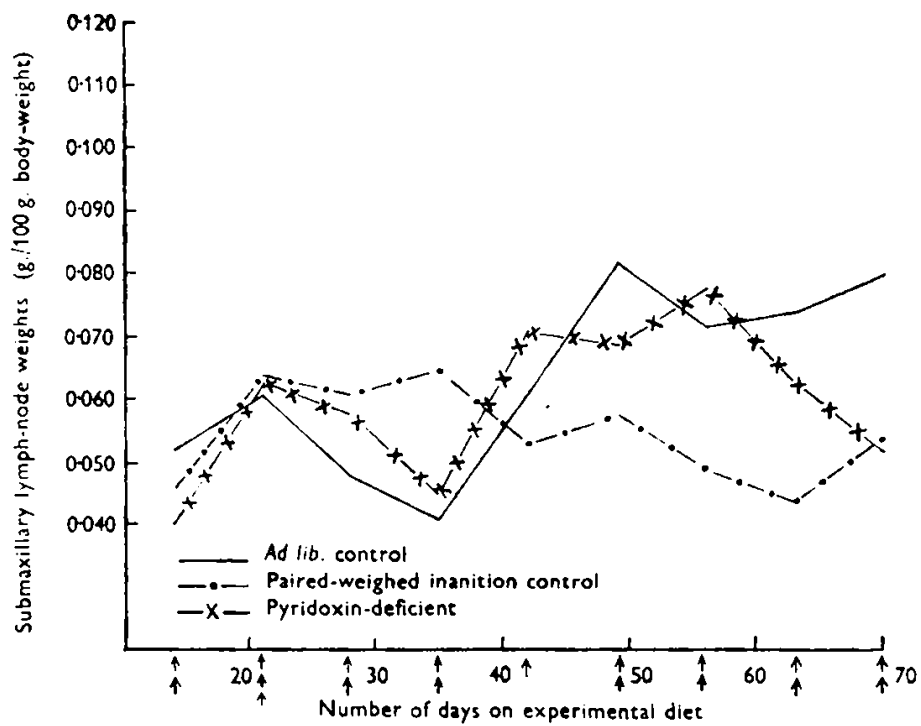

Fig. 3. Submaxillary lymph-node weights of pyridoxin-deficient rats and of ad lib. and pairedweighed controls, killed after $14-70$ days on experiment. $\uparrow=$ Trio of rats (see text, p. 321). 
The weights of the adrenal glands of the pyridoxin-deficient rats were not signifcantly greater than those of the corresponding inanition control rats (Fig. 5). Further, histological examination of frozen sections of the adrenals stained with Sudan dyes did not reveal signs of depletion of cortical lipoids. These findings suggest that, whatever the mechanism of the thymic atrophy in pyridoxin deficiency may be, pyridoxin

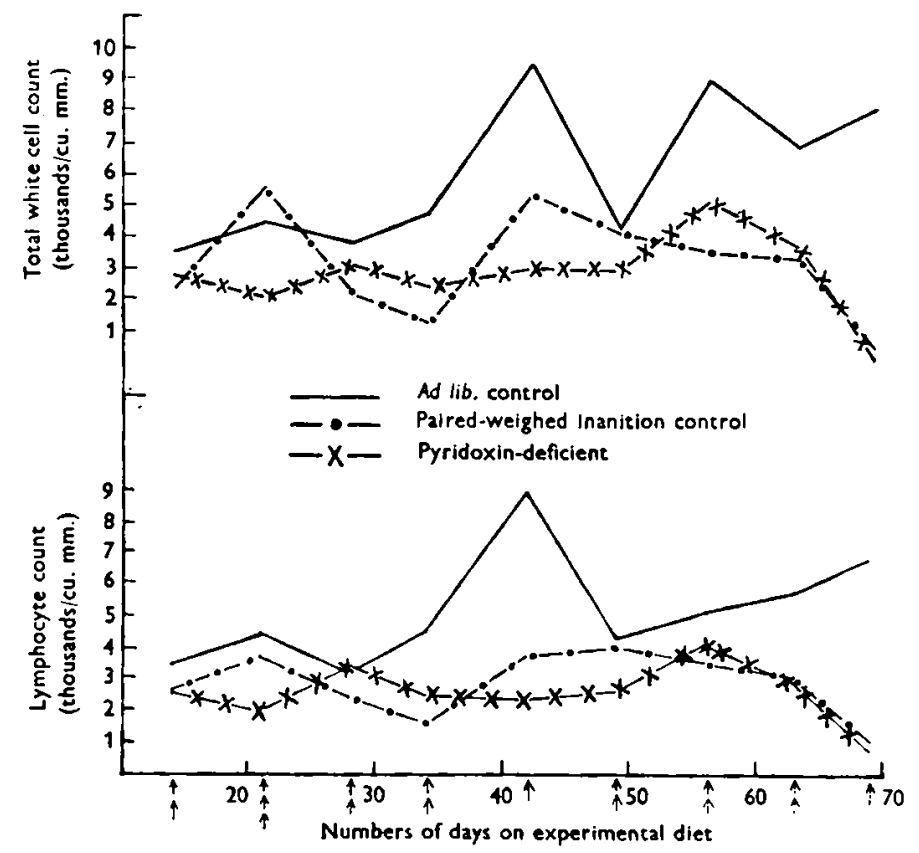

Fig. 4. Total white cell counts (above) and lymphocyte counts (below) of pyridoxin-deficient rats and of ad lib. and paired-weighed controls, killed after $\mathrm{I}_{4}-70$ days on experiment. $\hat{\imath}=$ Trio of rats (see text, p. 32I).

deficiency does not act as a noxious stimulus and cause a modified 'alarm response' (Selye, 1946) and thus initiate thymic atrophy by virtue of increased elaboration of adrenal cortical hormone secondary to augmented production of adrenocorticotrophic hormone by the anterior lobe of the pituitary. This confirms the work of Deane \& Shaw (1947). Preliminary experiments (Agnew, unpublished data) on the effect of adrenalectomy on the weights of the thymus glands of pyridoxin-deficient rats have also tended to confirm these observations.

\section{DISCUSSION}

The data presented in Table 2 suggest that a deficiency of pyridoxin can cause a striking reduction in circulating haemagglutinins. Our results thus confirm those of Stoerk \& Eisen (1946) and Stoerk et al. (1947) who also used sheep erythrocytes, and of Axelrod et al. (1947) who used human erythrocytes as an antigenic stimulus. Our experiments on the antibody response in rats after injection of a killed culture, ' $\mathrm{H}$ ' antigen, of Bact. typhosum (Table 3) indicate that pyridoxin deficiency caused a poor antibody response after injection of this antigen also. There is some doubt about the 
specificity of pyridoxin deficiency in causing an impaired antibody response. Stoerk et al. (1947) observed impaired antibody production in pyridoxin deficiency alone, and not in deficiency of aneurin, riboflavin, or pantothenic acid. Axelrod et al. (1947), however, with human erythrocytes as antigen, reported just as poor an antibody response in pantothenic acid deficiency, and Carter \& Axelrod (1948) noted a diminished antibody response in aneurin-deficient rats. These workers suggest that the reason for the differences between their results and those of Stoerk et al. (1947) may have been due to the difference in strength of the antigenic stimulus used.

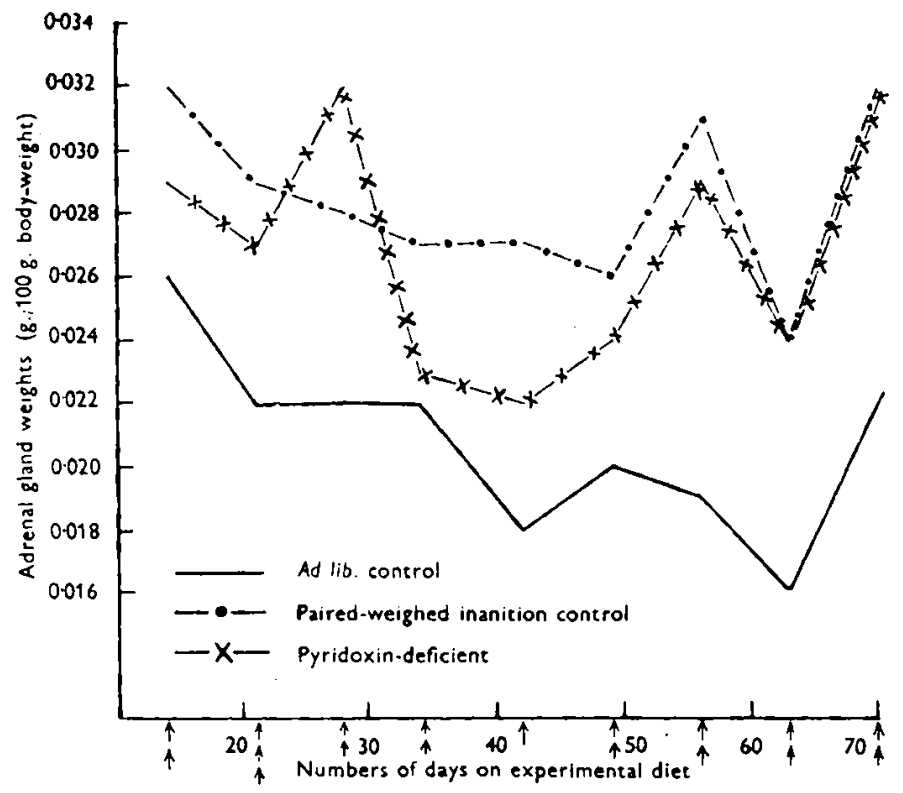

Fig. 5. Adrenal gland weights of pyridoxin-deficient rats and of ad lib. and paired-weighed controls, killed after $14-70$ davs on experiments. $\uparrow=$ Trio of rats (see text, p. 321 ).

The recent demonstration of the importance of the lymphocyte and lymphoid tissue in antibody elaboration (see, e.g. White \& Dougherty, 1946) might suggest that the impaired antibody response in pyridoxin deficiency is secondary to the '...striking loss of fixed and circulating lymphocytes...' (Stoerk et al. 1947). But it was only in the thymus that we observed changes which could be described as 'striking'. Only slight depletion of lymphocytes was noted in the spleens and submaxillary lymph nodes and these organs (Figs. 2 and 3 ) were not lighter than the corresponding organs of inanition and $a d$ lib. controls. Indeed, the spleens of the pyridoxin-deficient rats were, if anything, heavier than those of the corresponding controls. Further, with regard to the number of circulating lymphocytes, we did not observe any significant difference between the counts in the pyridoxin-deficient animals and their corresponding inanition controls. It may well be, however, that our technique of making only a single blood count in each animal just before death was not sufficiently representative, and that consecutive blood counts in the same animal during the period on the diet would have been more informative. Thymic atrophy is well marked in pyridoxin deficiency although lesser degrees of 
atrophy have been noted, e.g. in deficiency of aneurin, riboflavin, and pantothenic acid. Stoerk et al. (1947) reported that histologically cortico-medullary differentiation was not lost in the thymus of an aneurin-deficient rat as it usually was in a pyridoxin-deficient animal $(\mathrm{Pl} . \mathrm{I}, 2)$, and that the effect of aneurin deficiency on lymphoid tissue was not so pronounced. Further, as mentioned above, despite the atrophy of lymphoid tissue, antibody production in the aneurin-deficient rat was unaffected. It would seem that the poor antibody response in pyridoxin-deficient rats is not secondary to atrophy of lymphoid tissue. Pyridoxin is of importance in protein metabolism, e.g. in tryptophan metabolism, and as a coenzyme in the decarboxylation of tyrosine, and it may be, as suggested by Stoerk et al. (1947), through interference with some phase of amino-acid metabolism that deficiency of pyridoxin causes an impaired antibody response and that the 'lymphoid atrophy occurring in pyridoxine deficiency could conceivably be a consequence of defective globulin synthesis rather than its cause' (Stoerk et al. 1947, P. 370).

That our inanition control rats exhibited antibody titres at least as high as those of the ad lib. fed rats (Tables 2 and 3 ) is of interest because of the fairly severe restriction of food intake. Stoerk et al. (1947) reported a similar tendency in their animals. Cannon and his colleagues (e.g. Cannon, Chase \& Wissler, 1943) have stressed the importance of a low-protein diet in rabbits as a cause of diminished capacity to elaborate antibodies. The type of animal used and the degree of food restriction, particularly of protein, may well have been responsible for these conflicting results but further work on this problem is desirable.

Evans (1948) tested the antibody response in patients with radiation-induced lymphopenia and in a series of reticulo-endothelioses comprising cases of myelocytic and lymphatic leukaemia, Hodgkin's disease, lymphosarcoma and lymphofollicular reticulosis. He observed a very poor agglutinin response except in the myelocytic leukaemias, and attributed this to the degree of disorganization in the lymph glands in these conditions. Although administration of pyridoxin might be of value in such cases the rationale for such therapy is not clear-cut. In the reticulo-endothelioses there is some evidence that administration of pyridoxin might be harmful. Dubin (1947) found that generally there was a poor antibody response in patients with Hodgkin's disease. He had read Stoerk \& Eisen's (1946) paper on the poor antibody response of pyridoxin-deficient rats injected with sheep erythrocytes, and not unnaturally thought that administration of pyridoxin might stimulate antibody production in one of his cases of Hodgkin's disease. Accordingly, he began treatment with $150 \mathrm{mg}$. of pyridoxin daily in addition to Röntgen therapy. At the outset he noted (p. 9ro) that the patient's 'general condition was rather good'. Treatment continued until the patient died 2 months later. Dubin was struck (p. 910 ) by 'the rapid worsening' of his patient, and the change in histological appearance of the lesions which showed transition from less to more active growth. He wondered if the pyridoxin had actually accelerated growth of the neoplastic tissue. Stoerk (1947) has reported that lymphosarcoma implants failed to develop in pyridoxin-deficient mice and that marked regression of lymphosarcoma implants occurred when mice were depleted of pyridoxin. Thus, although a poor antibody response may occur in the reticulo-endothelioses, it seems unwise at 


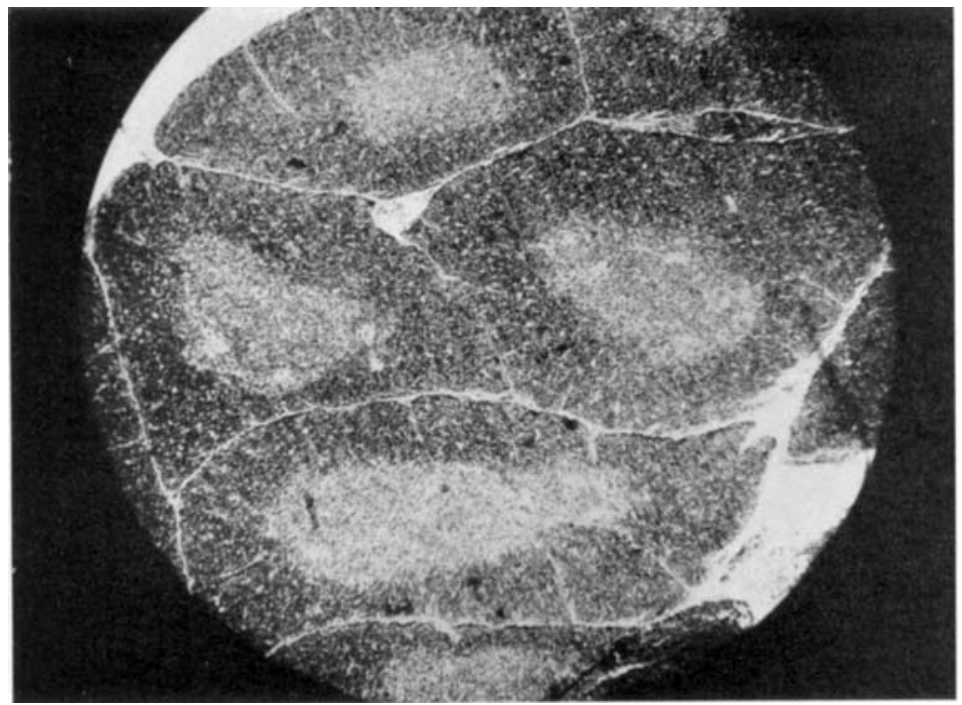

1. Normal rat thymus showing cortico-medullary differentiation. $\times 30$.

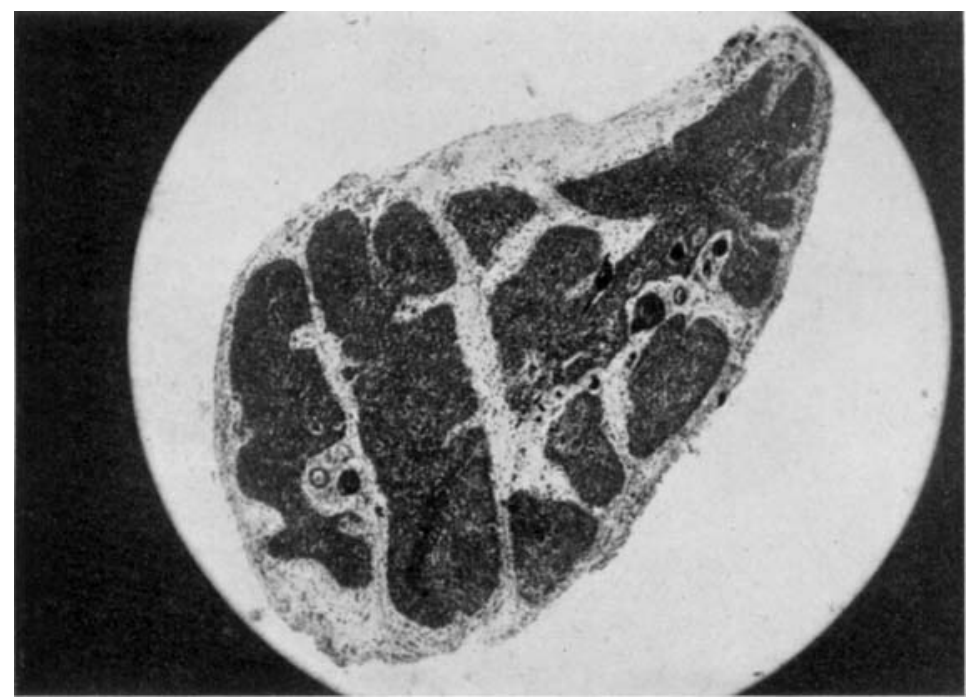

2. Thymus of pyridoxin-deficient rat. Note absence of cortico-medullary differentiation and separation of the atrophic lobules by thickened trabeculas. $\times 30$. 
present to attempt to improve antibody production by giving pyridoxin. Indeed it is possible that benefit might follow if the tissues were actually depleted of pyridoxin by administering an antivitamin (desoxypyridoxin) and studies on the human requirements of pyridoxin in the reticulo-endothelioses are now being undertaken in collaboration with Prof. H. W. Fullerton of Aberdeen University.

\section{SUMMARY}

I. The antibody response of pyridoxin-deficient rats injected with sheep erythrocytes or a killed culture, ' $\mathrm{H}$ ' antigen, of Bact. typhosum, was significantly lower than that of similarly treated inanition and $a d$ lib. control animals. Inanition control rats exhibited antibody titres at least as high as those of the corresponding $a d$ lib. fed animals.

2. The thymus glands of pyridoxin-deficient rats were significantly lighter than those of corresponding inanition and $a d$ lib. control rats and marked depletion of lymphocytes resulting in a loss of cortico-medullary differentiation was observed histologically.

3. No significant differences were observed in the weights of the spleens and submaxillary lymph nodes of the pyridoxin-deficient rats compared with inanition and ad lib. controls, although slight depletion of the number of lymphocytes, particularly in the lymph nodes, was observed.

4. No significant differences were observed in the total white cell count and the lymphocyte count between pyridoxin-deficient rats and their corresponding inanition controls, although both these counts were generally lower than counts obtained in ad lib. control rats.

5. The effect of pyridoxin deficiency on lymphoid tissue did not appear to be mediated through a pituitary-adrenal mechanism.

6. The relationship between lymphoid tissue and antibody formation is briefly considered, and the possible clinical significance of pyridoxin discussed.

One of us (L.R.C.A.) was in receipt of a full-time Agricultural Research Council Scholarship.

We wish to thank Mr G. Porter and his staff for their skilful and careful handling of the animals, Mr F. Baker for the photomicrographs, and Mr E. A. S. Rattray for his help in many aspects of the work.

\section{REFERENCES}

Agnew, L. R. C. (1 948). Nature, Lond., 161, 205.

Axelrod, A. E., Carter, B. B., McCoy, R. H. \& Geisinger, R. (1947). Proc. Soc. exp. Biol., N. Y., $66,137$.

Cannon, P. R., Chase, W. E. \& Wissler, R. W. (1943). F. Immunol. 47, 133.

Carter, B. B. \& Axelrod, A. E. (1948). Proc. Soc. exp. Biol., N.Y., 67, 416.

Deane, H. W. \& Shaw, J. H. (1947). F. Nutrit. 34, 1.

Dubin, I. N. (1947). Ann. intern. Med. 27, 898 .

Evans, R. W. (1948). F. Path. Bact. 60, 123.

Selye, H. (1946). F. Clin. Endocrinol. 6, I17.

Stoerk, H. C. (1947). Y. biol. Chem. r71, 437.

Stoerk, H. C. \& Eisen, H. N. (1946). Proc. Soc. exp. Biol., N. Y., 62, 88.

Stoerk, H. C., Eisen, H. N. \& John, H. M. (1947). F. exp. Med. 85, 365.

White, A. \& Dougherty, T. F. (1946). Ann. N.Y. Acad. Sci. 46, 859. 